\title{
Article
}

\section{Female Undergraduate's Perceptions of Intrusive Behavior in 12 Countries}

Sheridan, L, Scott, A, Archer, John and Roberts, K

Available at http://clok.uclan.ac.uk/17623/

Sheridan, L, Scott, A, Archer, John ORCID: 0000-0003-0483-1576 and Roberts, $K$ (2017) Female Undergraduate's Perceptions of Intrusive Behavior in 12 Countries. Aggressive Behavior, 46 (6). pp. 531-543. ISSN 0096-140X

It is advisable to refer to the publisher's version if you intend to cite from the work. http://dx.doi.org/10.1002/ab.21711

For more information about UCLan's research in this area go to

http://www.uclan.ac.uk/researchgroups/ and search for <name of research Group>.

For information about Research generally at UCLan please go to http://www.uclan.ac.uk/research/

All outputs in CLoK are protected by Intellectual Property Rights law, including Copyright law. Copyright, IPR and Moral Rights for the works on this site are retained by the individual authors and/or other copyright owners. Terms and conditions for use of this material are defined in the policies page.

\section{CLoK}

Central Lancashire online Knowledge www.clok.uclan.ac.uk

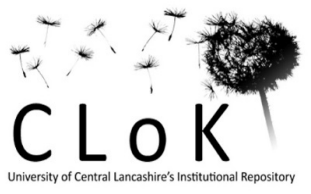




\section{AGGRESSIVE BEHAVIOR}

\section{Female Undergraduates' Perceptions of Intrusive Behavior in 12 Countries}

\begin{tabular}{|r|l|}
\hline Journal: & Aggressive Behavior \\
\hline Manuscript ID & AB-16-070.R1 \\
\hline Wiley - Manuscript type: & Research Article \\
\hline Date Submitted by the Author: & 07-Mar-2017 \\
\hline Complete List of Authors: & $\begin{array}{l}\text { Sheridan, Lorraine; Curtin University, Psychology } \\
\text { Scott, Adrian; Edith Cowan University, School of Law and Justice } \\
\text { Archer, John; University Of Central Lancashire, Psychology } \\
\text { Roberts, Karl; University of Western Sydney, School of Social Sciences \& } \\
\text { Psychology }\end{array}$ \\
\hline Keywords: & stalking, cross-national, gender equality, parasite-stress, Hofstede \\
\hline &
\end{tabular}

SCHOLARONE ${ }^{\text {m }}$

Manuscripts 


\begin{abstract}
The present study examines young women's $(N=1,734)$ perceptions of the unacceptability of 47 intrusive activities enacted by men. Female undergraduate psychology students from 12 countries (Armenia, Australia, England, Egypt, Finland, India, Indonesia, Italy, Japan, Portugal, Scotland, Trinidad) indicated which of 47 intrusive activities they considered to be unacceptable. Responses were compared with parasite-stress values, a measure of global gender equality and Hofstede's dimensions of national cultures. There was no unanimous agreement on any of the items, even for those relating to forced sexual violence. Cluster analysis yielded four clusters: 'Aggression and surveillance' (most agreement that the constituent items were unacceptable), 'Unwanted attention,' 'Persistent courtship and impositions,' and 'Courtship and information seeking' (least agreement that the constituent items were unacceptable). There were no significant relationships between the 'Aggression and surveillance' or 'Courtship and information seeking' clusters and the measure of gender equality, Hofstede's dimensions of national cultures or the measure of parasite stress. For the 'Unwanted attention' and 'Persistent courtship and impositions' clusters, women residing in countries with higher gender inequality and higher parasite-stress were less accepting of behavior associated with uncommitted sexual relations, and women in more individualistic societies with higher levels of gender equality were less accepting of monitoring activities. Culture may take precedence over personal interpretations of the unacceptability of intrusive behavior that is not obviously harmful or benign in nature.
\end{abstract}

Keywords: stalking, cross-national, gender equality, parasite-stress, Hofstede. 


\section{Female Undergraduates' Perceptions of Intrusive Behavior in 12 Countries}

The majority of research concerning the intrusive behavior commonly referred to as stalking has been conducted in Australia, the United Kingdom, and the United States, with little research being conducted in non-English speaking countries or making cross-national comparisons. The present study examines young women's perceptions of 47 intrusive activities and compares responses from female psychology undergraduate students living in 12 countries. Cluster analyses of country-level perceptions regarding the unacceptability of the intrusive activities are related to a measure of gender equality, Hofstede's dimensions of national cultures, and a measure of parasite-stress. These country-level perceptions are also compared to country-level experiences of the same 47 intrusive activities, based on data from a previous study (Sheridan, Scott \& Roberts, 2016), to determine whether an association exists between perceptions and experiences of intrusive behavior.

Prior research has used two principal methods to examine variables associated with how stalking and stalking-related behavior are perceived, namely vignette studies and the presentation of lists of intrusive activities, many of which have been previously identified as constituents of stalking. Taken together, the findings from the vignette-based studies indicate a number of commonly held perceptions in community, student and police samples from Australia, Canada, the United Kingdom and the United States. The primary finding is a negative relationship between perceptions of the seriousness of stalking and the degree of prior intimacy between the stalker and the victim (e.g., Cass, 2011; Curci et al., 2005; Hills \& Taplin, 1998; Phillips et al., 2004; Scott, Lloyd, \& Gavin, 2010; Scott, Rajakaruna, Sheridan, \& Sleath, 2014; Scott \& Sheridan, 2011; Scott et al., 2013; Sheridan, Gillett, Davies, 
Blaauw, \& Patel, 2003; Sheridan, Scott, \& Nixon, 2016; Weller, Hope, \& Sheridan, 2013).

The other principal method of examining perceptions of stalking and intrusive behavior involves respondents reading through a list of intrusive activities and indicating those they believe to constitute stalking, or consider to be unacceptable (see Chapman \& Spitzberg, 2003; Jagessar \& Sheridan, 2004; Lambert, Smith, Geistman, Cluse-Tolar, \& Jiang, 2013; McKeon, McEwan, \& Luebbers, 2015; Pereira, Matos, Sheridan, \& Scott, 2015; Sheridan, Davies, \& Boon, 2001; Sheridan, Gillett, \& Davies, 2000; Sheridan, Gillett, \& Davies, 2002; Yanowitz, 2006). These works were conducted in Australia, Japan, Portugal, Trinidad, the United Kingdom, and the United States. Collectively, their findings indicate that respondents generally share ideas concerning the type of individual acts that constitute stalking or are unacceptable, despite not employing common definitions or methodologies. Some intercultural contrasts have been noted, however. For example, Jagessar and Sheridan (2004) compared British and Trinidadian women's judgments of 42 intrusive activities, finding that higher ratings of unacceptability were provided by the British women for 29 of the 42 intrusive activities (69\%).

One possible explanation for cross-cultural differences in perceptions and also experiences of stalking is individualism-collectivism (individualism). Chapman and Spitzberg (2003) compared the incidence of common forms of stalking behavior between samples of university students from Japan and the United States. Of those who had been "persistently pursued," more US than Japanese participants (41\% vs. $34 \%$ ) were likely to believe their experiences constituted stalking. However, significantly more Japanese than US students perceived their experiences as threatening, a difference that was particularly pronounced in men (11\% vs. $40 \%)$. The 
authors suggested that this finding could due in part to the collectivist nature of Japanese society, in that a threat to the individual could be magnified by the perception that it constituted a threat to their friendship group. This suggestion requires further examination in additional country samples. Self-selected victims of stalking were surveyed in three European countries by Galeazzi, Bučar-Ručman, De Fazio, and Groenen (2009), who found more similarities than differences in the course and nature of the victims' experiences. However, it could be argued that the three countries (Belgium, Italy and Slovenia) share a similar culture.

Another reason for comparing samples from different countries is the strong Anglo-Saxon bias within the existing stalking-related literature. As Chapman and Spitzberg (2003) indicated, analyses based only on samples from individualist cultures cannot be generalized to collectivist cultures. Henrich, Heine, and Norenzayan (2010) argued that most psychological research is based on Western, Educated, Industrialised, Rich and Democratic (WEIRD) samples, and that it tends to generalize results to other cultures and samples without advising readers about the limitations of such inferences. Analysis of samples from six sub-disciplines in psychology revealed that $96 \%$ of participants were from WEIRD countries (e.g., Australia, Europe, and the United States). Studies conducted within Trinidad and Portugal (both strongly collectivist cultures) demonstrated largely similar perceptions of 47 intrusive activities to those found within English samples (a more individualistic culture). Where differences did occur, they were between the collectivist cultures and the individualistic culture (Jagessar \& Sheridan, 2004; Pereira, Matos, Sheridan, \& Scott, 2015).

Hofstede's pioneering research identified four other dimensions of culture in addition to individualism: these were power distance, masculinity-femininity 
(masculinity), uncertainty avoidance, and long-term orientation (Hofstede, 1984).

People within collectivist cultures value the needs of the group over the individual (Markus \& Kitayama, 1991), deriving a sense of self from close kinship and friendships (Hofstede, 1980). Conversely, people within individualistic cultures place their personal goals above those of their in-groups (Chen \& West, 2008), and are less emotionally dependent on kinships or friendships (Hofstede, 1980). Furthermore, women in collectivist cultures are traditionally expected to be passive, with aggressive courtship approaches by men considered acceptable (Chapman \& Spitzberg, 2003). As such, it could be argued that women in more collectivist countries would be more accepting of intrusive behavior by men than those in individualistic cultures. Power distance is the extent of power disparity between the highest and lowest social groups. Masculinity concerns societal preferences for achievement and assertiveness versus modesty and quality of life. Uncertainty avoidance is a culture's tolerance for ambiguity and uncertainty. Long-term orientation refers to whether a culture is more inclined to value long-term outcomes over short-term ones (Hofstede, 2011). All these variables will be included in the present work.

Our previous related study (Sheridan et al., 2016) explored the relationship between young women's experiences of intrusive behavior, their relative gender empowerment as reflected by the Gender Empowerment Measure (GEM; see United Nations Development Programme Human Development Report, 1997) and Hofstede's dimensions of national culture. The present study uses the same sample of respondents, but explores another part of the same dataset, covering responses from 12 countries. Whereas the previous analysis involved experiences of intrusive behavior, the present analysis focuses on cross-cultural differences in the perceptions 
of this same behavior. Sheridan et al. (2016) found that women from countries scoring lower on the GEM were more likely to experience intrusive behavior that was severe, such as forced sexual contact, being spied upon and being pestered via repeated attempts at communication. In contrast, women from countries with higher GEM scores were more likely to experience intrusive behavior that was innocuous, such as being asked for casual sex at social events, or being offered a social drink. Similarly, women from countries with lower individualism scores reported more severe intrusions, while women from countries with higher individualism scores reported more innocuous intrusions. The types of intrusions corresponding to gender empowerment and individualism scores showed a great deal of overlap and supported Archer's (2006) cross-cultural findings, which indicated that women's susceptibility to aggression from men varied inversely with both gender empowerment and individualism. The current work employs the World Economic Forum's Global Gender Gap Index (GGGI; Hausmann, Tyson, \& Zahidi, 2010) rather than the GEM. The GGGI is a newer measure designed to capture male-female differences independently of other cultural and socioeconomic factors (see Zentner \& Mitura, 2012). This aggregate measure also corrects for the influence of affluence and would appear to be the most comprehensive measure of gender equality available, comprising 14 indicators from political, economic, health and educational domains.

Via the parasite-stress theory of sociality, Fincher and Thornhill (2012) propose that variables such as individualism reflect national variations in parasite load. In a series of studies, Fincher, Thornhill, Murray, and Schaller (2008) found strong positive associations both within (United States) and between nations (e.g. Hong Kong and Nigeria) when indicators of assortative sociality (i.e. strong family ties and heightened religiosity) and levels of parasite-stress were compared. The 
parasite-stress theory of sociality posits that varying degrees of parasite and disease stress shape human qualities such as personality, political tendencies and propensity toward religiosity. Fincher et al. (2008) demonstrated that the unidimension of individualism at national levels tends to relate strongly to the prevalence of infectious disease. That is, high parasite-stress is associated with high collectivism (low individualism), and low parasite-stress is associated with low collectivism (high individualism). So, for example, it may be that the behavioral aspects of collectivism, including adherence to traditional values and a wariness of out-groups, have evolved as buffers against the dangers posed by the relatively higher risk of pathogen transmission. The current work employs the combined measure of parasite-stress values calculated by Fincher and Thornhill (2012). This measure combines the World Health Organisation's variable ‘Infectious Disease Disability Adjusted Life Years' and the Global Infectious Disease and Epidemiology Network's prevalence measure of human specific infectious diseases. The former is a cross-national measure of morbidity and mortality attributed to 28 different infectious and parasitic diseases. The latter is a cross-national indicator of parasite prevalence.

Disease avoidance may also relate to sociosexuality (i.e., individual differences in the willingness to engage in uncommitted sexual relations; Simpson \& Gangestad, 1991). As expected, people living within regions with histories of high levels of infectious disease have been identified as more likely to adopt a restricted sociosexual style, and this was particularly the case among women. The authors suggested that this heightened caution among women exists because any fitness benefits associated with unrestricted sociosexuality would be more readily overwhelmed by costs as disease prevalence increases. Simpson and Gangestad (1991) employed the socio-sexual orientation inventory to measure individual 
differences in the tendency toward an unrestricted approach to sexual relationships, with higher scores indicating greater comfort with casual sexual partners, and a heightened interest in obtaining new sexual partners. This seven-item inventory and the 47 intrusive activities employed by the present work include similar items, both asking about the perceived unacceptability of casual sexual encounters. Although not a measure of sociosexuality per se, our instrument may be able to provide an indication of whether greater sexual freedoms relate to a measure of gender equality, Hofstede's dimensions of national cultures, or a measure of parasite-stress. Apostolou (2015) argued that until recently, third parties (most often parents) regulated much of human evolution mate choice. He contends that in post-industrial societies, there is a stronger evolutionary pressure on mechanisms that enable individuals to attract and retain a mate, and that this has led to a wide variation in how these mechanisms work, and further that in some people, the mechanisms are dysfunctional. This potential explanation of intrusive behavior suggests a disparity between what the initiator and the recipient of the behavior may consider unacceptable.

The present work will compare perceptions and experiences of intrusive behavior. A small number of previous works have produced equivocal findings concerning the relationship between perceptions of stalking and intrusive activities, and experiences of same. Yanowitz (2006) presented a list of 25 potential acts of stalking to students in the United States, finding that women were more likely to perceive intrusive behavior as stalking than were men, as were those with personal experience of stalking victimization. More recently, Lambert et al. (2013) presented a list of potential acts of stalking behavior along with various attributes of stalking cases to 2,174 students in the United States, finding that women had more realistic 
perceptions of stalking than men, and that previous experience of stalking victimization did not moderate these sex differences.

The present study examines young women's perceptions of the unacceptability of 47 intrusive activities enacted by men, comparing data from women living in 12 countries to determine whether or not people from different nations hold similar ideas concerning which activities are unacceptable. Respondents were convenience samples of similarly aged undergraduate psychology students. The study did not use a direct measure of stalking because stalking is difficult to define (see e.g., Sheridan \& Davies, 2001), and because stalking is not in the common lexicon, or legislated against, within some of the countries included in the present study. As such, it would not be meaningful to ask women about their perceptions of 'stalking.' Instead, women were asked about their perceptions regarding the unacceptability of intrusive behavior, much of which represents forms of stalking. We note that male judgments of intrusive behavior are important and we will seek to examine these in the future. For now, we follow earlier work that has largely limited itself to women's judgments. Based on the evidence summarized above, we predicted that women residing in countries with higher gender inequality, more collectivist cultures and higher parasitestress would be more accepting of the more aggressively intrusive behavior, and less accepting of behavior associated with uncommitted sexual relations. Given mixed findings from two previous studies, we do not make any predictions concerning the relationship between perceptions and experiences of the 47 intrusive activities. 


\section{Method}

\section{Participants}

A combined sample of 1,734 female psychology undergraduate students participated in the present study, comprising 12 individual samples of young women from Armenia $(n=100, M=21.87$ years, $S D=3.29)$, Australia $(n=100, M=20.78$ years, $S D=2.01)$, Egypt $(n=100, M=22.76$ years, $S D=4.86)$, England $(n=100, M$ $=20.51$ years, $S D=3.25)$, Finland $(n=386, M=21.56$ years, $S D=4.78)$, India $(n=$ $100, M=20.02$ years, $S D=0.90)$, Indonesia $(n=102, M=20.29$ years, $S D=1.08)$, Italy $(n=195, M=21.78$ years, $S D=3.11)$, Japan $(n=98, M=19.39$ years, $S D=$ $0.60)$, Portugal $(n=253, M=20.23$ years, $S D=0.91)$, Scotland $(n=100, M=20.76$ years, $S D=2.01)$, and Trinidad $(n=100, M=21.67$ years, $S D=3.55)$. In eight of the countries, all respondents were lifelong residents of the country in which they resided. In four of the countries, the vast majority of respondents were lifelong residents: $98 \%$ in Finland and India, 93\% in Portugal, and 92\% in Japan.

\section{Materials}

The study employed a modified version of the 'Stalking: International perceptions and prevalence' questionnaire originally developed by Sheridan et al., (2001). The original and modified versions of the questionnaire (containing 42 and 47 intrusive activities respectively) have been used in eight previous studies (see Sheridan et al., 2016).

The questionnaire comprises three sections. Section 1 concerns respondents' demographic details including age, sex, nationality and country of birth. Section 2 considers respondents' perceptions of the unacceptability of 47 intrusive activities, with respondents being asked to indicate all those that they personally consider to be 
unacceptable (from the perspective of the target with the intrusive activities being enacted by men). Section 3 considers respondents' experiences of the same 47 intrusive activities, with respondents being asked to indicate all those that they have personally experienced. More detail concerning this aspect of the work is provided in Sheridan et al. (2016). The 47 intrusive activities were designed to represent a continuum of behavior and incorporated most of the intrusive activities included in the two most widely used measures of stalking (Unwanted Pursuit Behavior Inventory [UPBI], Langhinrichsen-Rohling, Palarea, Cohen, \& Rohling, 2000; Obsessive Relational Intrusion scale [ORI-P], Cupach \& Spitzberg, 1998). Some of the intrusive activities would be likely to cause suffering to the individual (e.g., death threats, forced sexual contact), whereas others would be likely to be considered routine and harmless in most cultures (e.g., asking someone out on a platonic date, doing unrequested favors for someone).

\section{Procedure}

Potential international research partners from university psychology departments in different countries were e-mailed with an invitation to collaborate in a study of international perceptions and incidence of harassment and stalking. An outline of the nature of harassment and stalking was provided, together with a summary of current international legislation and empirical research on stalking. There were 10 eventual partners, and the authors collected two further sets of data (in England and Scotland). These partners received a research-briefing document and were responsible for translating and back translating the questionnaires in order to maintain conceptual equivalence (see Straus, 1969). Partner researchers within each country provided questionnaires to a minimum of 100 volunteers during class time. 
Country leads were required to demonstrate that they met certain ethical standards, including the British Psychological Society's Code of Ethics and Conduct (2009). As far as possible, identical methodologies were employed at each site. No explanation or definition of stalking was included in the questionnaire in an effort to avoid priming effects. At the start of the survey, respondents were told "We are a group of researchers collecting data from a number of different countries. We are studying your views on unwanted attention." The term 'unwanted attention' was considered to have a broad remit and to be reflective of the 47 intrusive activities, as well as being less value-laden than for instance, 'harassment' or 'unwanted pursuit'. Prior to responding to the list of 47 intrusive activities, respondents were instructed as follows: "Please read through the list of behaviours below, and circle the numbers beside any you would consider to be unacceptable behaviours. That is, if a man directed these behaviours towards you, which would you find unacceptable?" Further details of the procedure are provided in Sheridan et al. (2016), dealing with the incidence data from Section 3 of the questionnaire.

\section{Data Analysis}

Research partners provided summaries of the data concerning the proportion of women who perceived each of the 47 intrusive activities to be unacceptable. Although three research partners returned questionnaires so that the authors could input the data, others only returned descriptive and frequency statistics. The nature of the data restricted the range of statistical analyses that could be employed. Responses to the 47 intrusive activities were subjected to cluster analysis at the variable level, using Ward's (1963) hierarchical agglomerative method. The dendrogram that was produced yielded four perception clusters, labeled 'Aggression and surveillance,' 
'Unwanted attention,' 'Persistent courtship and impositions,' and 'Courtship and information seeking.' Bivariate Spearman rank correlation analyses were then performed to examine the relationships between country-level perceptions regarding the unacceptability of the four perception clusters, the GGGI, Hofstede's (1979) dimensions of national cultures, and parasite-stress values.

\section{Results}

\section{Perceptions of Intrusive Behavior}

Consideration of the average proportions for the 12 countries revealed that the five intrusive activities most often perceived to be unacceptable were: 'Forced sexual contact' (97\%), 'Physically hurting someone you care about' (96\%), 'Making death threats' (95\%), 'Threatening to physically hurt you' (94\%), and 'Hurting you emotionally' (94\%). These acts are clearly detrimental in nature. The five intrusive activities least often perceived to be unacceptable were: 'Asking you out "as just friends"' (14\%), 'Talking about you to mutual friends after meeting you just once' $(15 \%)$, 'Telephoning you after one initial meeting' (16\%), 'Doing unrequested favors for you' $(16 \%)$, and 'A stranger engaging you in a conversation in a public place' (21\%). These activities are clearly more benign in nature. The proportion of respondents who perceived each of the 47 intrusive activities to be unacceptable is provided in the Appendix.

\section{Gender Equality, Hofstede's Dimensions of National Cultures, and Parasite- Stress}

Table 1 displays the GGGI, Hofstede's dimensions of national cultures, and the parasite-stress values for the 12 countries, and Table 2 displays the correlations 
between them. It is apparent that the GGGI is negatively correlated with the power distance index and the parasite-stress values; that the power distance index is further negatively correlated with the individualism index and positively correlated with the parasite-stress values; and that the individualism index is further negatively correlated with the parasite-stress values.

---Tables 1 and 2 about here---

\section{Cluster analyses}

Respondents' perceptions of the unacceptability of 47 intrusive activities were subjected to cluster analysis using Ward's (1963) hierarchical agglomerative method and the associated dendrogram yielded four perception clusters. The cluster analysis indicates that perceptions were similar for each of the acts within an individual cluster. The clusters, listed in Table 3, were interpreted as follows:

Cluster 1: Aggression and surveillance. The 19 acts that comprised this cluster were the most serious in terms of the impact they would likely have on a target. The acts included threats to harm or kill the target and persons close to the target, forced sexual activity, actual emotional and physical harm, vandalism and trespass, and 'classic stalking' behavior (see e.g. Jordan, Wilcox \& Pritchard, 2007). that included repeated communications and surveillance activities. Collectively, these intrusive activities were most likely to be perceived as unacceptable, with a large majority of respondents in all 12 countries judging them to be unacceptable.

Cluster 2: Unwanted attention. The seven acts that comprised this cluster dealt with unwanted attention that was not overtly aggressive nor surveillance based. The acts concerned standing and waiting outside the target's home and workplace or 
place of study, sending notes and parcels and other communications, and refusing to accept the end of a relationship. As such, this cluster was interpreted as covering unwanted attention that was not immediately threatening. A majority of respondents in eight of the 12 countries collectively judged these intrusive activities to be unacceptable.

Cluster 3: Persistent courtship and impositions. The nine acts that comprised this cluster dealt with persistent courtship and other impositions. The acts included engaging the target in inappropriate and intimate discussions, requests for sex, wolf-whistling, asking for dates repeatedly, and imposing social activities. These intrusive activities were judged to be unacceptable by a majority of respondents in just two of the 12 countries, likely as a consequence of many of these acts being relatively non-threatening when considered in isolation.

Cluster 4: Courtship and information seeking. The 10 acts that comprised this cluster were the least serious in terms of the impact they would be likely to have on a target. The acts concerned the gathering of target-related information and courtship, such as talking about a target to mutual friends, doing unrequested favors, gift giving, and seeking proximity to a target in a non-threatening manner. These intrusive activities were not judged to be unacceptable by a majority of respondents in any of the 12 countries.

Overall, the intrusive activities in cluster 1 were perceived to be the least acceptable, followed by the acts in clusters 2, 3, and 4. An inverse relationship was apparent for experiences, with the intrusive activities in cluster 4 being the most commonly experienced, followed by the acts in clusters 3,2 and 1 . It is important to acknowledge that this pattern held collectively, but did not apply to all individual 
countries. For example, Armenian women were more likely to have experienced the intrusive activities in cluster 2 than the acts in cluster 3.

Table 4 displays the correlation coefficients for the four perception clusters with the GGGI, Hofstede's dimensions of national cultures, and parasite-stress values. There were significant correlations for the 'Unwanted attention' cluster with the GGGI, power distance index, and parasite-stress values. Furthermore, there were significant correlations for the 'Persistent courtship and impositions' cluster with the GGGI, power distance index, individualism index and long-term orientation index. In contrast, there were no significant correlations for the 'Aggression and surveillance' and 'Courtship and information seeking' clusters with the GGGI, any of Hofstede's dimensions of national cultures, or parasite-stress values. Taken together, these results suggest that intrusive activities that were clearly judged to be the most ('Aggression and surveillance') or the least ('Courtship and information seeking') harmful and threatening were perceived similarly irrespective of cultural differences as measured by the GGGI, Hofstede's dimensions of national cultures and parasite-stress values. However, these cultural differences were associated with perceptions of intrusive activities where there was less universal agreement regarding their unacceptability ('Unwanted attention' and 'Persistent courtship and impositions').

---Tables 3 and 4 about here---

\section{Discussion}

The present study demonstrated that women's perceptions of the unacceptability of 47 intrusive activities differed across the 12 countries examined. Differences were even apparent for those intrusive activities judged most unacceptable. For example, 
there was no consensus regarding 'Forced sexual contact', with $84 \%$ of Armenian women perceiving this behavior to be unacceptable compared with 100\% of Egyptian, Indian and Scottish women. At the other end of the spectrum, differences were also apparent for the least unacceptable intrusive activities. For example, 2\% of Italian women perceived 'Asking you out as just friends' to be unacceptable compared with $42 \%$ of Egyptian women. Thus, it would appear that perceptions of intrusive behavior are related to culture.

Some clues concerning what to expect from the present work were gleaned from the limited previous research examining the association between culture and perceptions of intrusive behavior. As noted in the introduction, a study comparing Trinidadian and UK women found that higher ratings of unacceptability were provided by the British women for a majority (69\%) of 42 intrusive activities (Jagessar \& Sheridan, 2004). The present study produced similar findings, with higher ratings of unacceptability being provided by the British women than the Trinidadian women, for 27 of 47 intrusive activities (57\%). The present study also produced similar findings to Chapman and Spitzberg (2003), who compared the personal stalking experiences of students living in Japan and the United States. Chapman and Spitzberg found that Japanese students were significantly more likely than their American counterparts to judge their experiences as threatening. In the present study, the Japanese women provided the second highest ratings of unacceptability, when average proportions were calculated for perceptions across all 47 intrusive activities. Finnish women produced the highest ratings, and Italian women provided the lowest ratings of unacceptability.

A pattern was observed regarding the subtypes of intrusive behavior that were associated with gender equality, Hofstede's dimensions of national cultures and/or 
parasite-stress. The two clusters where there was less universal agreement that the constituent items were unacceptable ('Unwanted attention' and 'Persistent courtship and impositions') were correlated with a number of the measures, whilst the clusters containing items most ('Aggression and surveillance') and least ('Courtship and information seeking') likely to be judged as unacceptable were not. Women from more individualistic cultures characterized by comparatively high levels of gender equality were generally (but the pattern was imperfect) less tolerant of these 'grey area' activities. This suggests that these types of acts are those that best illustrate cultural differences. Behavior that presents an immediate threat and behavior that are most obviously benign in nature are universally identified as such, whilst cultural factors may impact the interpretation of those acts that fall between these extremes. These 'grey area' intrusive activities are likely to occur within the context of initiating a relationship, and may support Apostolou's (2015) assertion that in post-industrial societies there exists wide variation in mechanisms for attracting a mate, and, that in some people, the mechanisms may be dysfunctional. Further work on populations with greater and lesser degrees of parental control over mate choice is required to explore this potential relationship.

The 'Unwanted attention' cluster correlated with the GGGI, power distance and parasite-stress values. Respondents from countries with higher gender equality, less accepting of power distances and lower parasite-stress values were more likely to judge these cluster items as unacceptable. The latter finding provides some support for the parasite-stress theory of sociality in the present context, suggesting that higher parasite-stress promotes in-group assortative sociality, three general social components of which are: limited dispersal in terms of reproduction, favoring ingroups and avoiding out-groups (see Fincher \& Thornhill, 2012). The positive 
correlation between country-level judgments concerning the unacceptability of

'Unwanted attention' items and country-level parasite-stress values allows a tentative argument to be made that a higher parasite load is associated with the likelihood of greater tolerance of being monitored by men. The items in this cluster concerned the refusal to accept the termination of a relationship and following and watching a target and sending unwanted communications. We may speculate here that these activities would allow men to monitor the virtue of their target and could be motivated by an unwillingness to allow her to forge relationships outside of the relevant in-group. Further work could explore this specifically by taking a mixed methods approach that would allow an illustration of the context of various forms of intrusive behavior.

Conversely, the items that made up the 'Persistent courtship and impositions' cluster were more likely to be judged as unacceptable by women in countries with lower gender equality, more accepting of power distances, higher collectivism, and lower long-term orientation. The 'Unwanted attention' cluster focused on standing and waiting outside the target's home and workplace or place of study, sending notes and parcels and other communications, and refusing to accept the end of a relationship. The 'Persistent courtship and impositions' cluster concerned engaging the target in appropriate and intimate discussions, requests for sex, wolf-whistling, asking for dates repeatedly, and imposing social activities. Thus, women from Western countries had a lower acceptance of behavior associated with attempts to monitor them and seek proximity, whilst women from non-Western countries were less tolerant of discussions and behavior relating to sexual activity and dating. The notion of a Western versus non-Western split is a generalization based on the significant difference found in relation to individualism-collectivism, long term orientation and power distance scores. 
When cluster scores relating to perceptions and experiences of the 47 items were compared, those relating to the most ('Aggression and surveillance') and least ('Courtship and information seeking') unacceptable acts were close to significance. Those relating to the more 'grey area' activities were not close to statistical significance. This would further reinforce the suggestion that cultural interpretations may take precedence over personal interpretations when women assess these 'grey area' activities. The wider stalking literature, being based on mainly WEIRD samples (see Henrich, Heine, \& Norenzayan, 2010), has been known to make generalized suggestions concerning those variables that legislators should consider when drafting anti-stalking legislation, and these include type of stalking behavior and reaction of the victim (e.g. Ngo, 2014). The current findings would suggest that the adoption of a universal legislative model would not necessarily serve the needs of every culture, and indeed nor would any recommendations based on the interpretation of harm as a result of stalking that did not consider culture as a filter.

It is important when considering the findings of the present study to be aware of its limitations, which are similar to those discussed in Sheridan et al. (2016): the use of a non-random sample and self-reports, the possibility of substantial variation in the study sites and interpretation of the activities, and cultural biases in terms of disclosure. Further, a small sample of female students from a single university in a country does not necessarily provide an accurate representation of female students within that country. As such, the data need to be interpreted with caution. It is likely that a more representative sample would produce more clear-cut findings and a methodology that did not rely on self-report would allow more authoritative recommendations. Our respondents may have had a conservative response bias. Other limitations include the use of a female-only sample and the employment of Hofstede's 
dimensions of national cultures, which have attracted various forms of criticism. For example, it has been argued that the dimensions largely ignore context and individual difference (see Gerhart \& Fang, 2005). The present work used the dimensions, in conjunction with measures of gender equality and parasite-stress, as a framework to examine whether culturally-driven differences may be found in perceptions of the unacceptability of intrusive activities enacted by men.

In conclusion, the present study has indicated that culture may influence female undergraduate's perceptions of the unacceptability of intrusive behavior. Women residing in countries with higher gender inequality and higher parasite-stress were less accepting of behavior associated with uncommitted sexual relations, and women in more individualistic societies with higher levels of gender equality were less accepting of monitoring activities. This pattern did not apply to those activities that were most and least likely to be judged as unacceptable, suggesting that cultural influences apply to more 'grey area' intrusive behavior. Future work should adopt a mixed-methods approach with male and female respondents in order to collect data that includes context to illustrate how these perceptions are formed and expressed. 


\section{References}

Archer, J. (2006). Cross-cultural differences in physical aggression between partners: A social-role analysis. Personality and Social Psychology Review, 10, 133153. doi: $10.1207 / \mathrm{s} 15327957$ pspr1002_3

Apostolou, M. (2015). Past, present, and why people struggle to establish and maintain intimate relationships. Evolutionary Behavioral Sciences, 9, 257-269. doi:10.1037/ebs0000052

British Psychological Society (2009). Code of ethics and conduct. Leicester: British Psychological Society.

Cass, A. I. (2011). Defining stalking: The influence of legal factors, extralegal factors, and particular actions on judgments of college students. Western Criminology Review, 12, 1-14. Retrieved from http://wcr.sonoma.edu

Cass, A. I., \& Rosay, A. B. (2012). College student perceptions of criminal justice system responses to stalking. Sex Roles, 66, 392-404. doi: 10.1007/s11199011-9934-3

Chapman, D. E., \& Spitzberg, B. H. (2003). Are you following me? A study of unwanted relationship pursuit and stalking in Japan: What behaviors are prevalent? Hijiyama University Bulletin, 10, 89-117. Retrieved from http://www-rohan.sdsu.edu

Chen, F. F., \& West, S. G. (2008). Measuring individualism and collectivism: The importance of considering differential components, reference groups, and measurement invariance. Journal of Research in Personality, 42, 259-294. doi:10.1016/j.jrp.2007.05.006

Cupach, W. R., \& Spitzberg, B. H. (1998). Obsessive relational intrusion and stalking. In B. H. Spitzberg \& W. R. Cupach (Eds.), The dark side of close 
relationships (pp. 233- 263). Hillsdale, NJ: Lawrence Erlbaum Associates.

Curci, P., Fazio, L., Luberto, S., Secchi, C., Galeazzi, G. M., Neri, G., ... \& Farham, F. (2005). Recognition and perception of stalking by police officers and general practitioners: A multi-centre European study. In Modena Group on Stalking. (Eds.). Female victims of stalking. Recognition and intervention models: A European study (pp. 82-110). Milano: FrancoAngeli.

Fincher, C.L. \& Thornhill, R. (2012). Parasite-stress promotes in-group assortative sociality: The cases of strong family ties and heightened religiosity. Behavioral and Brain Sciences, 35, 61-119 (including commentaries)

Fincher, C.L., Thornhill, R., Murray, D.R., \& Schaller, M. (2008). Pathogen prevalence predicts human cross-cultural variability in individualism/collectivism. Proceedings of the Royal Society of London, Series B, 275, 1279-1285. http://dx.doi.org/10.1098/rspb.2008.0094.

Fischer, A.H. \& Manstead, A.S. (2000). The relation between gender and emotions in different cultures. In A.H. Fisher (Ed.), Gender and emotions: Social psychological perspectives (pp. 71-94). Cambridge, UK: Cambridge University Press.

Galeazzi, G. M., Bučar-Ručman, A., De Fazio, L., \& Groenen, A. (2009). Experiences of stalking victims and requests for help in three European countries. A survey. European Journal of Criminal Policy Research, 15, 243260.

Gerhart, B., \& Fang, M. (2005). National culture and human resource management: assumptions and evidence. The International Journal of Human Resource Management, 16, 971-986. doi: 10.1080/09585190500120772 
Hausmann, R., Tyson, L. D., \& Zahidi, S. (2012). The global gender gap index 2012. The Global Gender Gap Report, 3-27.

Henrich, J., Heine, S. J., \& Norenzayan, A. (2010). The weirdest people in the world? Behavioral and Brain Sciences, 33, 61-135. doi: $10.1017 / \mathrm{S} 0140525 \mathrm{X} 0999152 \mathrm{X}$

Hills, A., \& Taplin, J. (1998). Anticipated responses to stalking: Effect of threat and target-stalker relationship. Psychiatry, Psychology and Law, 5, 139-46. doi: $10.1080 / 13218719809524927$

Hofstede, G. (1979). Value systems in forty countries: Interpretation, validation and consequences for theory. In L. H. Eckensberger, W. J. Lonner \& Y. H. Poortinga (Eds.), Cross-cultural contributions to psychology. Lisse, Netherlands: Swets and Zeitlinger.

Hofstede, G. (1980). Motivation, leadership, and organization: Do American theories apply abroad. Organizational Dynamics, 9, 42-63. doi: 10.1016/00902616(80)90013-3

Hofstede, G. (1984). Culture's consequences: International differences in workrelated values. Newbury Park, CA: Sage.

Hofstede, G. (2011). Dimensionalizing cultures: The Hofstede model in context. Online Readings in Psychology and Culture, 2. doi: 10.9707/2307-0919.1014

Jagessar, J. D. H., \& Sheridan, L. P. (2004). Stalking perceptions and experiences across two cultures. Criminal Justice and Behavior, 31, 97-119. doi: 10.1177/ 0093854803259244

Jordan, C. E., Wilcox, P., \& Pritchard, A. J. (2007). Stalking acknowledgement and reporting among college women experiencing intrusive behaviors: Implications for the emergence of a "classic stalking case". Journal of 
Criminal Justice, 35, 556-569. doi: 10.1016/j.jcrimjus.2007.07.008

Lambert, E. G., Smith, B., Geistman, J., Cluse-Tolar, T., \& Jiang, S. (2013). Do men and women differ in their perceptions of stalking: An exploratory study among college students. Violence and Victims, 28, 195-209. doi: 10.1891/08866708.09-201

Langhinrichsen-Rohling, J., Palarea, R. E., Cohen, J., \& Rohling, M. L. (2000). Breaking up is hard to do: Unwanted pursuit behaviors following the dissolution of a romantic relationship. Violence and Victims, 15, 73-90.

Markus, H. R., \& Kitayama, S. (1991). Culture and the self: Implications for cognition, emotion, and motivation. Psychological Review, 98, 224-253. doi: 10.1037/0033-295X.98.2.224

McKeon, B., McEwan, T. E., \& Luebbers, S. (2015). 'It's not really stalking if you know the person": Measuring community attitudes that normalize, justify and minimize stalking. Psychiatry, Psychology and Law, 22, 291-306. doi: $10.1080 / 13218719.2014 .945637$

Pereira, F., Matos, M., Sheridan, L., \& Scott, A.J. (2015). Perceptions and personal experiences of unwanted attention among Portuguese male students. Psychology, Crime and Law, 21, 398-411. doi: 10.1080/1068316X.2014.989167

Phillips, L., Quirk, R., Rosenfeld, B., \& O’Connor, M. (2004). Is it stalking? Perceptions of stalking among college undergraduates. Criminal Justice and Behavior, 31, 73-96. doi: 10.1177/0093854803259251

Scott, A. J., Lloyd, R., \& Gavin, J. (2010). The influence of prior relationship on perceptions of stalking in the United Kingdom and Australia. Criminal Justice and Behavior, 37, 1185-1194. doi: 10.1177/0093854810378812 
Scott, A. J., Nixon, K., \& Sheridan, L. (2013). The influence of prior relationship on perceptions of stalking: A comparison of laypersons, non-specialist police officers and specialist police officers. Criminal Justice and Behavior, 40, 1434-1448. doi: 10.1177/0093854813494183

Scott, A. J., Rajakaruna, N., Sheridan, L., \& Sleath, E. (2014). International perceptions of stalking and responsibility: The influence of prior relationship and severity of behavior. Criminal Justice and Behavior, 41, 220-236. doi: $10.1177 / 0093854813500956$

Scott, A. J., \& Sheridan, L. (2011). "Reasonable" perceptions of stalking: The influence of conduct severity and the perpetrator-target relationship. Psychology, Crime and Law, 17, 331-343. doi: 10.1080/10683160903203961

Sheridan, L., \& Davies, G. M. (2001). Stalking: The elusive crime. Legal and Criminological Psychology, 6, 133-147. doi: 10.1348/135532501168244

Sheridan, L., Davies, G. M., \& Boon, J. C. W. (2001). Stalking: Perceptions and prevalence. Journal of Interpersonal Violence, 16, 151-167. doi: $10.1177 / 088626001016002004$

Sheridan, L., Gillett, R., \& Davies, G. M. (2000). Stalking: Seeking the victim's perspective. Psychology, Crime and Law, 6, 267-280. doi: $10.1080 / 10683160008409807$

Sheridan, L., Gillett, R. \& Davies, G. M. (2002). Perceptions and prevalence of stalking in a male sample. Psychology, Crime and Law, 8, 289-310. doi: $10.1080 / 10683160208401821$

Sheridan, L., Gillett, R., Davies, G. M., Blaauw, E., \& Patel, D. (2003). ‘There’s no smoke without fire': Are male ex-partners perceived as more 'entitled' to stalk 
than stranger or acquaintance stalkers? British Journal of Psychology, 1, 87-

98. doi: 10.1348/000712603762842129

Sheridan, L., Scott, A. J., \& Nixon, K. (2016). Police officer perceptions of harassment in England and Scotland. Legal and Criminological Psychology, 21, 1-14. doi: 10.1111/lcrp.12049

Sheridan, L., Scott, A. J., \& Roberts, K. (2016). Young women's experiences of intrusive behavior in 12 countries. Aggressive Behavior, 42, 41-53. doi: $10.1002 / \mathrm{ab} .21604$

Simpson, J. A., \& Gangestad, S. W. (1991). Individual differences in sociosexuality: evidence for convergent and discriminant validity. Journal of Personality and Social Psychology, 60(6), 870-883.

United Nations Development Programme. (1997). Human Development Report. New York: Oxford University Press.

United Nations. (2011, July 25). Human Rights Council. Compilation Prepared by the Office of the High Commissioner for Human Rights in Accordance with Paragraph 15 (b) of the Annex to Human Rights Council Resolution 5/1: Trinidad and Tobago.

Ward, J. H. (1963). Hierarchical grouping to optimize an objective function. Journal of the American Statistical Association, 58, 236-244. doi:10.2307/2282967

Weller, M., Hope, L., \& Sheridan, L. (2013). Police and public perceptions of stalking: The role of prior victim-offender relationship. Journal of Interpersonal Violence, 28, 320-339. doi: 10.1177/0886260512454718

Wood, J. T. (2001). The normalization of violence in heterosexual romantic relationships: Women's narratives of love and violence. Journal of Social and Personal Relationships, 18, 239-261. doi: 10.1177/0265407501182005 
Yanowitz, K. L. (2006). Influence of gender and experience on college students' stalking schemas. Violence and Victims, 21, 91-100. doi: 10.1891/08866708.21.1.91

Zentner, M., \& Mitura, K. (2012). Stepping out of the caveman's shadow: Nations' gender gap predicts degree of sex differentiation in mate preferences. Psychological Science, 23, 1176-1185. doi: 10.1177/0956797612441004 
Table 1. The Global Gender Gap Index, Hofstede's dimensions of national cultures, and parasite-stress values for the 12 countries

\begin{tabular}{|c|c|c|c|c|c|c|c|c|c|c|c|}
\hline Armenia & Australia & Egypt & England & Finland & India & Indonesia & Italy & Japan & Portugal & Scotland & Trinidad \\
\hline \multicolumn{12}{|c|}{ 1. Global Gender Gap Index (GGGI) } \\
\hline 0.66 & 0.74 & 0.59 & 0.74 & 0.84 & 0.66 & 0.66 & 0.69 & 0.65 & 0.71 & 0.74 & 0.72 \\
\hline \multicolumn{12}{|c|}{ 2. Power distance index (PDI) } \\
\hline N/Av & 36 & 70 & 35 & 33 & 77 & 76 & 50 & 54 & 63 & 35 & 47 \\
\hline \multicolumn{12}{|c|}{ 3. Individualism index (IDV) } \\
\hline N/Av & 90 & 25 & 89 & 63 & 48 & 14 & 76 & 46 & 27 & 89 & 16 \\
\hline \multicolumn{12}{|c|}{ 4. Masculinity index (MAS) } \\
\hline N/Av & 61 & 45 & 66 & 26 & 56 & 46 & 70 & 95 & 31 & 66 & 58 \\
\hline \multicolumn{12}{|c|}{ 5. Uncertainty avoidance index (UAI) } \\
\hline N/Av & 51 & 80 & 35 & 59 & 40 & 48 & 75 & 92 & 104 & 35 & 55 \\
\hline \multicolumn{12}{|c|}{ 6. Long-term orientation index (LTO) } \\
\hline N/Av & 31 & $\mathrm{~N} / \mathrm{Av}$ & 25 & 41 & 61 & $\mathrm{~N} / \mathrm{Av}$ & 34 & 80 & 30 & 25 & N/Av \\
\hline \multicolumn{12}{|c|}{ 7. Parasite-stress values (PSV) } \\
\hline-1.98 & -2.59 & 0.66 & -3.49 & -3.62 & 2.71 & 3.60 & -2.84 & -2.23 & -1.85 & -3.49 & 0.32 \\
\hline
\end{tabular}


Table 2. Correlations between the Global Gender Gap Index, Hofstede's dimensions of national cultures and parasite-stress values

\begin{tabular}{lccccccc}
\hline & GGGI & PDI & IDV & MAS & UAI & LTO & PSV \\
\hline GGGI & - & & & & & & \\
PDI & $-0.79^{* *}$ & - & & & & & \\
IDV & 0.50 & $-0.73^{*}$ & - & & & & \\
MAS & -0.31 & -0.16 & 0.33 & - & & & \\
UAI & -0.32 & 0.28 & -0.42 & -0.06 & - & & \\
LTO & -0.54 & 0.53 & -0.54 & 0.44 & 0.32 & - & \\
PSV & $-0.58^{*}$ & $0.87^{* *}$ & $-.074^{*}$ & -0.19 & -0.11 & 0.50 & -
\end{tabular}

Note. GGGI, Global Gender Gap Index; PDI, power distance index; IDV, individualism index; MAS, masculinity index; UAI, uncertainty avoidance index; LTO, long-term orientation index; PSV, parasitestress values. ${ }^{*} p<.05 .{ }^{* *} p<.01$. 
Table 3. Cluster analysis of young women's perceptions of intrusive activities across the 12 countries

\begin{tabular}{|c|c|c|}
\hline & $\begin{array}{l}\text { Total perceptions } \\
\text { cluster scores for } \\
\text { each country }\end{array}$ & $\begin{array}{l}\text { Equivalent } \\
\text { experiences scores } \\
\text { for each country }\end{array}$ \\
\hline \multicolumn{3}{|l|}{ Cluster 1: Aggression and surveillance } \\
\hline Forced sexual contact & Armenia: $74.8 \%$ & Armenia: $38.3 \%$ \\
\hline Physically hurting someone you care about & Australia: $92.4 \%$ & Australia: $16.9 \%$ \\
\hline Making death threats & Egypt: $87.6 \%$ & Egypt: $33.9 \%$ \\
\hline Threatening to kill himself or hurt himself if & England: $91.3 \%$ & England: $14.4 \%$ \\
\hline you refused to go out with him & Finland: $96.7 \%$ & Finland: $21.5 \%$ \\
\hline Harming you physically & India: $94.1 \%$ & India: $26.0 \%$ \\
\hline $\begin{array}{l}\text { Hurting you emotionally (verbal abuse, } \\
\text { ruining your reputation) }\end{array}$ & $\begin{array}{l}\text { Indonesia: } 92.1 \% \\
\text { Italy: } 87.2 \%\end{array}$ & $\begin{array}{l}\text { Indonesia: } 27.3 \% \\
\text { Italy: } 16.9 \%\end{array}$ \\
\hline Secretly taking your belongings & Japan: $93.2 \%$ & Japan: $11.5 \%$ \\
\hline Intercepting mail/deliveries & Portugal: $94.3 \%$ & Portugal: $13.1 \%$ \\
\hline Following you & Scotland: $90.6 \%$ & Scotland: $15.6 \%$ \\
\hline Criminal damage/vandalism to your property & Trinidad: $79.7 \%$ & Trinidad: $35.8 \%$ \\
\hline Trying to manipulate or force you into dating & & (No significant \\
\hline $\operatorname{him}$ & & correlation between \\
\hline Confining you against your will & & perceptions and \\
\hline Spying on you & & experiences, $r=.55$, \\
\hline Threatening to physically hurt you & & $p=.06, N=12)$ \\
\hline \multicolumn{3}{|l|}{ Trespassing on your property } \\
\hline \multicolumn{3}{|l|}{ Taking photographs of you without your } \\
\hline \multicolumn{3}{|l|}{ knowledge } \\
\hline \multicolumn{3}{|l|}{ Verbally abusing you } \\
\hline \multicolumn{3}{|l|}{ Acting in an angry manner when seeing you } \\
\hline $\begin{array}{l}\text { out with other men (your friends or romantic } \\
\text { partners) }\end{array}$ & & \\
\hline \multicolumn{3}{|l|}{ Multiple telephone calls which you don't want } \\
\hline \multicolumn{3}{|l|}{ Cluster 2: Unwanted attention } \\
\hline Standing and waiting outside your home & Armenia: $40.1 \%$ & Armenia: $43.7 \%$ \\
\hline Refusing to accept that a prior relationship is & Australia: $83.0 \%$ & Australia: $23.6 \%$ \\
\hline over & & Egypt: $37.9 \%$ \\
\hline
\end{tabular}




$\begin{array}{lll}\text { Leaving unwanted items for you to find } & \text { Egypt: 34.9\% } & \text { England: 21.7\% } \\ \text { Giving or sending you strange parcels } & \text { England: } 89.3 \% & \text { Finland: } 14.9 \% \\ \text { Sending you unwanted letters, notes, e-mail or } & \text { Finland: 82.6\% } & \text { India: 39.6\% } \\ \text { other written communications } & \text { India: } 64.0 \% & \text { Indonesia: } 37.3 \% \\ \text { Standing and waiting outside your school or } & \text { Indonesia: 29.6\% } & \text { Italy: 33.5\% } \\ \text { work place } & \text { Italy: 21.4\% } & \text { Japan: } 18.3 \% \\ \text { Driving, riding, or walking purposefully past } & \text { Japan: } 68.5 \% & \text { Portugal: } 18.6 \% \\ \text { your residence, school or work place } & \text { Portugal: 65.2\% } & \text { Scotland: 22.4\% } \\ & \text { Scotland: } 88.6 \% & \text { Trinidad: } 54.9 \% \\ & \text { Trinidad: } 80.3 \% & \text { (No significant } \\ & & \text { correlation between } \\ & & \text { perceptions and } \\ & & \text { experiences, } r=-.44, \\ & & p=.15, N=12 \text { ) }\end{array}$

Cluster 3: Persistent courtship and impositions

A man engages you in an inappropriate

personal and intimate discussion

A man at a social event such as a party asks

you if you would like to have sex with him

'Outstaying his welcome' in your home

Agreeing with your every word (even if you

were wrong)

'Wolf-whistling' in the street

Asking you for a date repeatedly

Making arrangements without asking you first

(e.g., booking a table at a restaurant)

Sending or giving you gifts

A stranger offering to buy you a drink in a

café, restaurant or bar
Armenia: $45.8 \%$

Australia: $25.6 \%$

Egypt: $81.0 \%$

England: $23.1 \%$

Finland: $53.4 \%$

India: $50.8 \%$

Indonesia: $71.2 \%$

Italy: $29.5 \%$

Japan: 54.6\%

Portugal: $48.8 \%$

Scotland: $21.9 \%$

Trinidad: $28.8 \%$
Armenia: $37.1 \%$

Australia: $42.4 \%$

Egypt: $38.3 \%$

England: $48.6 \%$

Finland: $27.9 \%$

India: $46.0 \%$

Indonesia: $41.3 \%$

Italy: $47.1 \%$

Japan: $16.6 \%$

Portugal: $28.4 \%$

Scotland: $45.1 \%$

Trinidad: $36.1 \%$

(No significant

correlation between

perceptions and

experiences, $r=-.50$,

$p=.10, N=12$ )

Cluster 4: Courtship and information seeking

Changing classes, offices or joining a new

group to be closer to you

Visiting places because he knows that you
Armenia: $26.3 \%$

Armenia: $46.0 \%$

Australia: $26.6 \%$

Australia: $53.2 \%$

Egypt: $18.1 \%$
Egypt: $64.4 \%$ 
may be there

Asking your friends, family, school or work

England: $25.4 \%$

Finland: $24.9 \%$

India: $16.6 \%$

Indonesia: $11.3 \%$

Italy: $8.0 \%$

Japan: $30.9 \%$

Portugal: $14.0 \%$

Scotland: $17.2 \%$

Trinidad: $30.9 \%$

public place: such as at a bus stop or in a cafe

Talking about you to mutual friends after

meeting you just once

Telephoning you after one initial meeting

Asking you out 'as just friends'
England: $48.9 \%$

Finland: $14.9 \%$

India: $66.2 \%$

Indonesia: $63.5 \%$

Italy: $53.9 \%$

Japan: $31.4 \%$

Portugal: $46.0 \%$

Scotland: $49.2 \%$

Trinidad: $45.2 \%$

(No significant correlation between

perceptions and

experiences, $r=-.56$,

$p=.06, N=12)$

Cluster 5: Did not cluster

Coming round to visit you, uninvited, on a N/A N/A

regular basis

Finding out information about you (phone

numbers, marital status, address, hobbies)

without asking you directly 
Table 4. Bivariate Spearman rank correlations for the four perception clusters with the Global Gender Gap Index, Hofstede’s dimensions of national cultures, and parasitestress values

\begin{tabular}{lccccccc}
\hline & \multicolumn{7}{c}{ Dimensions } \\
\cline { 2 - 8 } Perception clusters & GGGI & PDI & IDV & MAS & UAI & LTO & PSV \\
\hline 1. Aggression and surveillance & .23 & .04 & .10 & -.43 & .18 & .42 & -.10 \\
2. Unwanted attention & $.74^{* *}$ & $-.78^{* *}$ & $.60^{\dagger}$ & .17 & -.47 & -.61 & $-.61^{*}$ \\
3. Persistent courtship and & $-.68^{*}$ & $.62^{*}$ & $-.70^{*}$ & -.44 & .54 & $.90^{* *}$ & .55 \\
impositions & & & & & & & \\
4. Courtship and information & .09 & -.42 & .13 & .25 & .02 & .17 & -.19 \\
seeking & & & & & & & \\
\hline
\end{tabular}

Note. Correlations for GGGI include all 12 countries; correlations for PDI, IDV, MAS and UAI include 11 of the 12 countries (excludes Armenia); correlations for LTO include 8 of the 12 countries (excludes Armenia, Egypt, Indonesia, Trinidad). GGGI, Global Gender Gap Index; PDI, power distance index; IDV, individualism index; MAS, masculinity index; UAI, uncertainty avoidance index; LTO, longterm orientation index; PSV, parasite-stress values. ${ }^{*} p<.05 .{ }^{* *} p<.01$. 


\section{Appendix}

Table A1. Proportion (\%) of respondents who perceived each of the 47 intrusive activities to be unacceptable Intrusive behavior

Armenia Australia Egypt England Finland India Indonesia Italy Japan Portugal Scotland Trinidad

1. Aggression and surveillance

Forced sexual contact

Physically hurting someone you care about

Making death threats

Threatening to kill himself or hurt himself if you refused to go out with

$\begin{array}{cccccccccccc}84 & 98 & 100 & 99 & 98 & 100 & 98 & 99 & 98 & 99 & 100 & 95 \\ 88 & 100 & 100 & 100 & 99 & 100 & 91 & 96 & 97 & 98 & 97 & 91 \\ 96 & 100 & 94 & 91 & 98 & 97 & 100 & 96 & 99 & 99 & 87 & 76 \\ 59 & 79 & 65 & 75 & 98 & 90 & 98 & 92 & 99 & 96 & 87 & 69\end{array}$

him

Harming you physically

Hurting you emotionally (verbal abuse, ruining your reputation)

Secretly taking your belongings

Intercepting mail/deliveries

Following you

Criminal damage/vandalism to your property

Trying to manipulate or force you into dating him

Confining you against your will

Spying on you

Threatening to physically hurt you

Trespassing on your property

Taking photographs of you without your knowledge

Verbally abusing you

Acting in an angry manner when seeing you out with other men (your

$\begin{array}{llllllllllll}74 & 99 & 89 & 97 & 99 & 96 & 97 & 96 & 95 & 99 & 98 & 85 \\ 100 & 95 & 97 & 88 & 99 & 99 & 98 & 92 & 98 & 94 & 91 & 78 \\ 82 & 97 & 96 & 97 & 98 & 95 & 96 & 91 & 96 & 94 & 96 & 85 \\ 81 & 95 & 97 & 92 & 97 & 98 & 98 & 93 & 96 & 95 & 95 & 71 \\ 77 & 94 & 92 & 97 & 95 & 94 & 94 & 89 & 96 & 95 & 95 & 96 \\ 80 & 85 & 99 & 74 & 99 & 99 & 98 & 96 & 97 & 99 & 68 & 65 \\ 77 & 93 & 93 & 98 & 98 & 95 & 97 & 82 & 81 & 96 & 97 & 78 \\ 72 & 99 & 75 & 97 & 98 & 91 & 82 & 92 & 97 & 95 & 95 & 77 \\ 76 & 96 & 82 & 96 & 97 & 92 & 85 & 89 & 93 & 92 & 94 & 78 \\ 69 & 98 & 100 & 99 & 98 & 100 & 99 & 96 & 98 & 99 & 94 & 83 \\ 67 & 97 & 84 & 95 & 88 & 91 & 86 & 84 & 96 & 94 & 95 & 91 \\ 90 & 92 & 82 & 98 & 90 & 94 & 85 & 59 & 93 & 87 & 95 & 86 \\ 39 & 67 & 73 & 62 & 98 & 88 & 97 & 87 & 95 & 99 & 58 & 40 \\ 51 & 82 & 54 & 86 & 97 & 83 & 70 & 83 & 53 & 92 & 84 & 88\end{array}$


friends or romantic partners)

Multiple telephone calls which you don't want to receive

$\begin{array}{llllllllllll}60 & 90 & 93 & 94 & 95 & 85 & 79 & 46 & 95 & 70 & 96 & 83\end{array}$

2. Unwanted attention

Standing and waiting outside your home

Refusing to accept that a prior relationship is over

Leaving unwanted items for you to find

Giving or sending you strange parcels

Sending you unwanted letters, notes, e-mail or other written

communications

Standing and waiting outside your school or work place

Driving, riding or walking purposefully past your residence, school or

(2)

90

$93 \quad 94$

$\begin{array}{llllllllllll}54 & 90 & 24 & 93 & 90 & 78 & 24 & 32 & 88 & 81 & 94 & 62 \\ 60 & 80 & 28 & 85 & 94 & 77 & 53 & 21 & 84 & 57 & 79 & 68 \\ 19 & 87 & 50 & 96 & 79 & 77 & 34 & 19 & 96 & 71 & 96 & 92 \\ 35 & 74 & 57 & 93 & 83 & 49 & 39 & 23 & 69 & 70 & 93 & 86 \\ 23 & 89 & 64 & 94 & 83 & 75 & 29 & 22 & 7 & 70 & 96 & 82\end{array}$

\section{Persistent courtship and impositions}

A man engages you in an inappropriate personal and intimate discussion

A man at a social event such as a party asks you if you would like to have

$\begin{array}{llllllllllll}41 & 80 & 14 & 90 & 82 & 48 & 16 & 19 & 75 & 67 & 85 & 87 \\ 49 & 81 & 7 & 74 & 68 & 44 & 13 & 15 & 61 & 40 & 77 & 85\end{array}$
sex with him

'Outstaying his welcome' in your home

Agreeing with your every word (even if you were wrong)

'Wolf-whistling' in the street

Asking you for a date repeatedly

Making arrangements without asking you first (e.g., booking a table at a restaurant)

Sending or giving you gifts

$\begin{array}{lccccccccccc}56 & 40 & 92 & 43 & 84 & 53 & 87 & 52 & 72 & 87 & 36 & 31 \\ 96 & 31 & 100 & 28 & 71 & 67 & 99 & 44 & 97 & 88 & 22 & 32 \\ 22 & 33 & 90 & 19 & 63 & 76 & 88 & 41 & 60 & 63 & 21 & 25 \\ 14 & 5 & 65 & 7 & 78 & 12 & 60 & 43 & 68 & 40 & 7 & 29 \\ 88 & 25 & 98 & 27 & 50 & 78 & 95 & 39 & 40 & 26 & 21 & 17 \\ 37 & 37 & 61 & 34 & 41 & 38 & 46 & 13 & 50 & 48 & 36 & 30 \\ 16 & 22 & 60 & 25 & 40 & 27 & 32 & 19 & 48 & 40 & 28 & 22 \\ 39 & 25 & 76 & 19 & 35 & 56 & 62 & 4 & 3 & 12 & 23 & 64\end{array}$


A stranger offering to buy you a drink in a cafe, restaurant or bar

4. Courtship and information seeking

Changing classes, offices or joining a new group to be closer to you

Visiting places because he knows that you may be there

Asking your friends, family or work colleagues about you

Seeing him at the same time each day

Trying to get to know your friends in order to get to know you better

Doing unrequested favors for you

$\begin{array}{llllllllllll}44 & 12 & 87 & 6 & 19 & 50 & 71 & 10 & 53 & 34 & 3 & 9\end{array}$

A stranger engaging you in a conversation in a public place: Such as at a

$31 \quad 40$

$40 \quad 8 \quad 31$

$\begin{array}{llllllllllll}14 & 64 & 6 & 59 & 23 & 19 & 11 & 7 & 44 & 18 & 45 & 72\end{array}$

$\begin{array}{llllllllllll}17 & 29 & 3 & 27 & 28 & 11 & 8 & 22 & 39 & 28 & 18 & 34 \\ 41 & 17 & 4 & 27 & 32 & 21 & 9 & 11 & 40 & 16 & 22 & 37\end{array}$

$\begin{array}{llllllllllll}39 & 44 & 9 & 40 & 28 & 13 & 7 & 9 & 28 & 14 & 29 & 36\end{array}$

$\begin{array}{llllllllllll}11 & 22 & 3 & 16 & 24 & 17 & 1 & 9 & 35 & 13 & 10 & 29\end{array}$

bus stop or in a cafe

Talking about you to mutual friends after meeting you just once

Telephoning you after one initial meeting

$\begin{array}{llllllllllll}29 & 11 & 49 & 15 & 8 & 23 & 19 & 5 & 45 & 12 & 11 & 20\end{array}$

Asking you out 'as just friends'

$\begin{array}{lccccccccccc}13 & 15 & 26 & 14 & 13 & 17 & 23 & 5 & 18 & 6 & 12 & 20 \\ 37 & 17 & 31 & 14 & 10 & 14 & 11 & 1 & 21 & 6 & 9 & 21 \\ 31 & 7 & 42 & 11 & 15 & 14 & 10 & 2 & 11 & 4 & 9 & 14\end{array}$

\section{Cluster 5: Did not cluster}

Coming round to visit you, uninvited, on a regular basis

Finding out information about you (phone numbers, marital status,

$\begin{array}{llllllllllll}33 & 48 & 13 & 31 & 88 & 17 & 7 & 39 & 70 & 63 & 27 & 60 \\ 14 & 50 & 19 & 48 & 60 & 26 & 14 & 36 & 77 & 58 & 44 & 55\end{array}$

address, hobbies) without asking you directly

\begin{tabular}{llllllllllllll}
\hline Average unacceptability & 52 & 62 & 61 & 62 & 70 & 62 & 58 & 47 & 68 & 63 & 59 & 59 &
\end{tabular}

